\title{
BANALIZACIÓN DE LA VIOLENCIA
}

\author{
BANALITY OF VIOLENCE
}

\author{
Pablo Caldera Ortiz \\ DOI: 10.26754/ojs_arif/a.rif.202024355
}

J.L. Nancy, Banalidad de Heidegger. Madrid: Trotta, 2019, 93 pp.

Ante la publicación de varios volúmenes de los Cuadernos negros de Martin Heidegger, Jean-Luc Nancy se ha propuesto revisar las relaciones del filósofo alemán, comúnmente citado como el más importante del siglo veinte, con el nacionalsocialismo. Aunque ya Jean-François Lyotard en Heidegger y los judios (1995) o Pierre Bourdieu en La ontología política de Martin Heidegger (1988) habían tratado el tema, la novedad de la aproximación de Nancy radica en que este aplica el concepto de banalidad para explicar el supuesto antisemitismo del pensador. Así, el enfoque desde la banalidad arendtiana que ofrece Nancy nos recuerda que este no es un concepto moral cuyo referente es el mal, sino un concepto abierto, explicativo, que se refiere a la pregunta por la posibilidad del mal. La pregunta, en este caso, no supone un análisis psicológico de la personalidad del pensador sino un intento de comprender cómo este pudo no solo pasar por alto, sino también, según Nancy, aprovecharse del clima antisemita de la época. Es ahí, en ese intento de comprender lo incomprensible, donde opera el concepto de banalidad. Nancy no dibuja a Heidegger como un pensador esencial o primordialmente racista o nazi, simplemente pretende dilucidar por qué llegó a tolerar el antisemitismo de aquella manera, qué lo llevó a dejar de lado a todo un pueblo incluso tras su desencanto con el nazismo, por qué pervivió en él cierta forma de "archifascismo".

Los cuadernos negros comenzaron a publicarse en 2014. Banalidad de Heidegger, recién traducido por Jordi Massó en la editorial Trotta, se publicó en francés un año después. El análisis parte del concepto de desarraigo referido al proyecto heideggeriano de un nuevo comienzo. Este "nuevo comienzo" conlleva, explica Nancy, «la necesidad de un pueblo capaz de propiciarlo». Así pues, el pueblo judío resulta un actor primordial en este "desarraigo del ser" que marca la lectura heideggeriana de la historia. Esta pérdida de arraigo, este distanciamiento de lo 
humano a partir de la técnica, que encuentra su antagonismo fundamental en el pueblo griego, aquellos que consiguieron "definirse desde el ser", parece ser, según explica Nancy, culpa única y exclusivamente del pueblo judío.

El pueblo judío aparece en los Cuadernos negros como el «agente identificable» del Abendland, la decadencia de Occidente, el oscuro atardecer clausurado. Pero ¿por qué los judíos y no los americanos, los ingleses o los comunistas rusos, pueblos por los que Heidegger tampoco tenía simpatía, y que sin duda participan del dominio de la técnica? Esto es debido a que, desde siempre, los judíos conforman un cuerpo social mucho más identificable, fundado sobre sí mismo, y también mucho más antiguo: el pueblo nómada, desarraigado: un pueblo caracterizado por la Bodenlosigkeit o falta de suelo. El "pueblo judío" es tomado así como un agente singular, lo que favorece la proliferación de estereotipos antisemitas: «en el caso de Heidegger, el antisemitismo no era solo algo habitual en su ambiente, sino que a este ambiente pertenecía toda una línea de pensamiento en cierto sentido tradicional: el pensamiento del pueblo, el de una historia cuyos momentos y flexiones pertenecen a sus pueblos en cuanto sujetos singulares, incluso excepcionales» (p. 39). El problema, por tanto, reside en el hecho de haber ontologizado un pueblo, de haber desvanecido la verdad del antisemitismo en un proyecto metafísico que no era capaz de excluir lo político, de haber ligado la deconstrucción de una ontología metafísica con la destrucción de todo un pueblo culpabilizado de un olvido. En el movimiento de autodestrucción de Occidente — porque Occidente siempre fue, para Heidegger, decadencia: está en su etimología - y destrucción de la metafísica se alinean el antisemitismo y el proyecto filosófico de Heidegger. Nancy no duda en afirmar que para Heidegger «el pueblo judío pertenece de modo esencial al proceso de destrucción del mundo» (p. 33), quizás por ser la figura histórica más identificable. Así pues, mientras que Grecia marca el "primer comienzo", pues «se arriesgaron a definirse desde el ser», la decadencia también ha de ser comprendida desde la aparición de un agente reconocible. Heidegger acude, según Nancy, al mito de la conspiración tan extendido por la Europa de los años veinte, materializado en los Protocolos de los sabios de Sión.

Ahora bien, ¿cómo explica Nancy la complementariedad entre las aparentes posiciones antisemitas y el proyecto filosófico de Heidegger? Para el pensador francés, se trata de un movimiento que primero culpa al pueblo judío como agente activo de la decadencia de Occidente y, más tarde, liga «la deconstrucción (Abbau) de la ontología metafísica (...) con la destrucción (Zerstörung) de aquello y de aquellos que le parecía que destruían el mundo y la historia» (p. 39). Occidente requeriría una destrucción doble para poder instaurar un "nuevo comienzo" y el judío es, 
por su condición histórica, la figura más antigua culpable de la autodestrucción de Occidente. El pueblo judío participa del proceso de destrucción del mundo y, en tanto que agente desarraigado, supone para Heidegger una figura destacable y altamente perceptible. Si el desvelamiento es siempre inicial, el velamiento también tiene que proceder de una cierta figura, y esta es sin duda la del pueblo judío.

En la relación entre venida (Geschehen) y envío (Geschick) del ser, diferencia de base de la filosofía de Heidegger, también juega el pueblo judío un papel fundamental. El "nuevo comienzo" que se hace necesario ante la destrucción de Occidente es incompatible con el carácter de desarraigo. Así pues, a no ser que desaparezca lo que, en esencia, caracteriza a Occidente, el segundo comienzo se hace imposible. El primer comienzo es esencialmente griego, ya que "ellos" fueron los que se arriesgaron a definirse desde el ser. Igual que un pueblo propició aquel comienzo, el segundo comienzo exige otro pueblo capaz de propiciarlo. Argumenta Nancy que Heidegger "deseaba la autodestrucción” de Occidente porque estaba en su propio seno, en su propia etimología, y porque le parecía la única manera posible de construir un "nuevo comienzo" (p. 59). La autodestrucción de los judíos sería así el primer paso para el necesario nuevo comienzo, «pues por medio de la auto-supresión de lo carente-de-suelo es como puede advenir la victoria "de la Historia sobre lo carente-de-historia”» (p. 65). ¿Cómo reaccionar, entonces, ante la evidencia destructiva de los campos de concentración? Nancy sostiene, en un arriesgado ejercicio exegético, que «Heidegger no solo fue antisemita: quiso pensar hasta sus últimas consecuencias la necesidad innata e histórico-destinal del antisemitismo» (p. 67). Ahí juega un papel importante la banalidad, capaz de cegar ante el horror: Heidegger aprovechó el mito que por entonces circulaba, aquel de la sucia conspiración judía, para salir del paso. Más que una indagación sobre los núcleos antisemitas de la filosofía heideggeriana, Nancy elabora una extensión del concepto de banalidad y su relación con el horror. Es el retrato de la irresponsabilidad intelectual.

Así pues, Nancy no busca aquí inyectar culpa sobre Heidegger ni mirar con recelo su filosofía, sino entender por qué un intelectual como él incurrió en el antisemitismo de una manera tan burda e irresponsable. Para evitarlo, Nancy propone "aprender a existir sin ser y sin destinación": sustraer al ser de su destinación, eliminar la exigencia de "nuevos comienzos". Su análisis, al unir en uno de los núcleos del pensamiento heideggeriano su proyecto filosófico con un innegable antisemitismo, también puede leerse como una refutación sincera de sus ideas. Aún así, el propósito principal nace de un intento de eliminar, de una vez por todas, el antisemitismo inconsciente de ciertos pensadores europeos: cuando 
Nancy pretende explicar el nacimiento del antisemitismo como algo que está en el seno del cristianismo, en la configuración de la identidad cristiana, llega a decir que indagar las raíces del antisemitismo supone "actuar en el corazón mismo de nuestra cultura" (p. 74).

El libro consta de un "añadido" que versa sobre las relaciones entre judaísmo y cristianismo, el surgimiento del primero a partir del segundo y la imposibilidad de renunciar a este. El cristianismo se sitúa así, concluye Nancy, en un double bind en relación con el judaísmo: es judío y no-judío a la vez. Sin embargo, no duda en afirmar que el fundamento del antisemitismo es cristiano, "concretamente paulino" (p. 90): el cristianismo necesitaba rechazar su procedencia y afirmarse como autoengendrado.

Pese a su brevedad, Jean-Luc Nancy realiza una meticulosa argumentación que ayuda a reconducir, tras las incursiones de Faye, Bourdieu y Lyotard, la candente cuestión de la relación entre uno de los filósofos más importantes del siglo XX y el régimen nacionalsocialista.

\section{Pablo Caldera Ortiz. Universidad Autónoma de Madrid calderaorti_@gmail.com}

